\title{
INTERNACIONALIZACIÓN SIN «MODERNIZACIÓN»: EL CASO DEL MINISTERIO DE RELACIONES EXTERIORES DE CHILE
}

Internationalization without «modernization»:

the case of the Chilean Ministry of Foreign Relations

\author{
Claudio FuENTES \\ Facultad Latinoamericana de Ciencias Sociales-Chile \\ $\bowtie$ direccion@flacso.cl
}

BIBLID [1130-2887 (2007) 46, 97-117]

Fecha de recepción: enero del 2007

Fecha de aceptación y versión final: mayo del 2007

RESUMEN: El artículo examina una aparente paradoja: desde la transición a la democracia se produjo una alta y dinámica internacionalización de Chile expresada en cambios en términos políticos, sociales y económicos, proceso que no ha tenido una esperada transformación burocrática-institucional en el Ministerio de Relaciones Exteriores. Los intentos de reforma han fracasado y el statu quo ha prevalecido. Mientras alguna literatura institucionalista explicaría esta situación debido a resistencias «burocráticas» internas al cambio, en este trabajo se desarrollan dos argumentaciones centrales: factores inhibidores del contexto político (timing electoral e incentivos políticos) y de tipo organizacional (divisiones burocráticas internas y eficientes respuestas de agencias de gobierno a las demandas de la internacionalización). La investigación intenta aportar a la literatura al definir condiciones inhibidoras de una transformación institucional. El caso muestra una adaptación institucional sin modernización.

Palabras clave: política exterior, modernización del Estado, Chile, política burocrática, cambio institucional.

ABSTRACT: This article examines an apparent paradox: even though, since the transition to democracy in Chile, the country has experienced a significant political, economic, and social internationalization, this transformation has not been followed by an expected adaptation of State bureaucratic institutions toward such challenges. In particular, several attempts to reform the Ministry of Foreign Affairs in Chile have failed and the statu quo has prevailed. While some authors may explain this outcome due to bureaucratic resistance, this work suggests two intertwined set 
of explanations: inhibitor factors of the political context (electoral timing and political incentives) and organizational elements (divisions within the professional services and efficient parallel responses of the State to international challenges). This article attempts to make a contribution to the literature, suggesting specific inhibitor conditions for institutional transformation. The case exemplifies an institutional adaptation without modernization.

Key words: foreign policy, modernization of the State, Chile, bureaucratic politics, institutional change.

\section{INTRODUCCIÓN ${ }^{1}$}

La literatura institucionalista ha llamado la atención sobre las determinantes que favorecen u obstaculizan el cambio burocrático (Mintzberg, Brian y Voyer, 1997; Zurbriggen, 2006). Factores de orden político y del contexto parecen ser determinantes para encontrar condiciones favorables para una transformación. Asimismo, transformaciones en el orden de prioridades de los actores objeto de una transformación podrían generar condiciones favorables a un cambio.

En este artículo se examinan los factores inhibidores del cambio institucional. Desde el tránsito a la democracia en Chile en 1990, las autoridades políticas establecieron como prioridad la modernización de la Cancillería. Asimismo, se generó uno de los más dinámicos procesos de internacionalización económica y política que ha significado un salto cualitativo y cuantitativo en su inserción al mundo. Paradójicamente, esta fuerte internacionalización no ha sido acompañada por una consecuente transformación de la burocracia que acompaña a dicha internacionalización. Así, observamos una brecha importante o un desfase entre una alta internacionalización y ausencia de cambios institucionales en el ministerio -y particularmente en el servicio exterior- para responder a las crecientes demandas de este nuevo contexto.

El cambio en el contexto, sin embargo, no ha implicado una completa inercia. Algunos cambios sí se han producido, aunque en forma segmentada y no necesariamente en forma coherente. De hecho, la respuesta institucional más común ha sido la creación de burocracias profesionales paralelas que dan respuestas ad hoc a determinadas necesidades de la política exterior.

En este artículo se plantea que tres factores principales han inhibido procesos de modernización: el timing político, la existencia de una división al interior del servicio exterior sobre el sentido de la modernización y la propia existencia de burocracias paralelas eficientes que han reducido la prioridad del cambio. El desfase entre un contexto internacional dinámico y un servicio exterior donde no se producen cambios institucionales provoca crecientes distancias entre la autoridad política y los funcionarios de carrera: un juego de suma cero que debilita a dicha corporación.

1. Este trabajo forma parte del proyecto FONDECYT 1050228 (2005). Se basa parcialmente en otro trabajo del autor titulado «Diplomacia a vías paralelas: respuestas institucionales a la internacionalización de Chile» (en prensa). El autor agradece el apoyo en esta investigación de Natalia Escobar sobre recopilación de información, realización de entrevistas con actores claves y sugerencias bibliográficas. Asimismo, agradezco los comentarios de Augusto Varas y, en particular, a los revisores anónimos de América Latina Hoy, Revista de Ciencias Sociales, por sus sugerencias. 
En la primera parte de este trabajo se da cuenta del proceso de internacionalización política y económica de Chile en los últimos 16 años. Luego, se analiza por qué, pese a esta necesidad, los esfuerzos por modernizar el Ministerio de Relaciones Exteriores han fracasado hasta el momento. En otros términos, el aumento de demandas ha llevado a las autoridades a fortalecer instancias de apoyo técnico y político sin llegar a transformar las estructuras burocráticas existentes.

Lo anterior ha provocado soluciones organizacionales en lo que la literatura conoce como «burocracias paralelas», esto es, la existencia de cuerpos técnicos altamente preparados y que se transforman en mecanismos que intentan responder a las demandas emergentes. La transformación y modernización administrativa se ve postergada producto de una compleja red de intereses y circunstancias que hace difícil transformar el statu quo organizacional. Observamos un proceso de internacionalización sin una planificada modernización, donde se generan condiciones de suma cero entre los actores políticos y funcionarios de carrera que buscan optimizar sus beneficios de corto plazo.

\section{EL CONTEXTO DE INTERNACIONALIZACIÓN}

En los últimos 16 años, Chile observó un acelerado proceso de internacionalización motivado principal pero no únicamente por la estrategia de inserción económica internacional. Gran parte del dinamismo se explica por una política sistemática de ampliación de mercados que se ha materializado a partir de la firma de acuerdos de libre comercio, asociación económica y otros instrumentos para la facilitación del comercio. De la misma forma, la política exterior chilena ha incentivado un mayor protagonismo en foros internacionales y la vinculación estratégica con países «afines». Como resultado de este proceso, se ha incrementado la demanda sobre el Estado y las instituciones.

Desde el punto de vista económico, la política de internacionalización de la economía chilena, política denominada de «regionalismo abierto», se convirtió en el pilar fundamental de la estrategia chilena de apertura al mundo. En gran parte debido a la naturaleza del régimen, el modelo aperturista de la década de 1980 se sustentaba en la unilateralidad. Esta fórmula tenía una limitación básica: no exigía reciprocidad y, por lo tanto, no contribuía a la apertura de otros mercados (Van Klaveren, 1998). Una vez restablecida la democracia, la diplomacia chilena impulsó una triple estrategia de inserción que combinaba estrategias unilaterales, multilaterales y bilaterales.

$\mathrm{Al}$ comienzo, se puso un fuerte acento en la dimensión económica de la política exterior con una visión latinoamericana no excluyente a la apertura global. El establecimiento de acuerdos comerciales fue una prioridad de los gobiernos de la coalición de centro-izquierda que ha gobernado el país desde el establecimiento democrático². Tal como lo sostenía el ministro de Relaciones Exteriores José Miguel Insulza:

2. Patricio Aylwin (1990-1994), Eduardo Frei (1994-2000), Ricardo Lagos (2000-2006) y Michelle Bachelet (2006-2010). 
[...] una prioridad clave de la política exterior del presidente Frei es la internacionalización de la economía chilena, es decir, de los esfuerzos de política exterior destinados a fortalecer y ampliar nuestra presencia internacional, en los planos del comercio y la inversión extranjera. Un país abierto al mundo como el nuestro debe vincular necesariamente los intereses de su inserción internacional a sus relaciones exteriores. La dimensión económica de la política exterior adquiere así un carácter prioritario (Insulza, 1998: 18).

La intensidad de la actividad comercial de Chile queda graficada en que, en el período 1990-2005, se firmaron 8 acuerdos de libre comercio, 11 acuerdos de complementación económica, 38 acuerdos de protección a las inversiones, 16 acuerdos de doble tributación y 38 acuerdos aerocomerciales para la facilitación del tránsito de bienes, servicios y personas (Cuadro I).

CuAdro i. Tratados de Libre Comercio

Y ACUERDOS DE COMPLEMENTACIÓN ECONÓMICA DE CHILE 1990-2006

\begin{tabular}{c|c|c}
\hline Tratados de Libre Comercio & $\begin{array}{c}\text { Acuerdos de Complementación } \\
\text { Económica }\end{array}$ & Otros acuerdos suscritos \\
\hline Canadá 1996 & Argentina 1991 & \\
México 1998 & Bolivia 1993 \\
Centroamérica 1999 & Colombia 1993 & Protección inversiones: \\
Corea del Sur 2003 & Ecuador 1994 1993 & 38 países \\
EFTA(1) 2003 & MERCOSUR 1996 & Doble tributación: \\
Estados Unidos 2003 & Cuba 1998 (parcial) & 16 países \\
China 2005 & Perú 1998 & Aerocomercial: \\
Panamá 2006 & Unión Europea 2002 & 38 países \\
Perú 2006 & P4 (2) 2005 & \\
& India 2006 (parcial) & \\
\hline
\end{tabular}

(1) EFTA: La Asociación Europea de Libre Comercio, Islandia, Liechtenstein, Noruega y Suiza.

(2) P4: Nueva Zelanda, Singapur, Brunei Darussalam y Chile.

Fuente: Dirección General de Relaciones Económicas Internacionales. Ministerio de Relaciones Exteriores de Chile. http://www.direcon.cl. 2006.

Pero la internacionalización no se ha limitado solamente al intercambio comercial y la firma de acuerdos de libre comercio. A las importantes cifras en términos de inversión extranjera en Chile, se suma la inversión chilena en el extranjero, esta última localizada principalmente en el Cono Sur. Desde 1990 hasta el 2004, se invirtieron casi 15.000 millones de dólares en Argentina, 4.000 en Perú, 5.000 en Brasil y 2.000 en Colombia, lo cual totaliza una cifra cercana a los 30.000 millones de dólares. En el año 2004, Chile fue el tercer inversionista extranjero latinoamericano -después de Brasil y México-, denotando la importancia de los privados en los temas de relaciones regionales y especialmente vecinales. 
Como resultado de este período la economía chilena se erige como una de las más abiertas del mundo. Al menos así lo demuestra el índice de libertades económicas que ubica a Chile en el número 11 de un ranking que incluye a 110 países (Miles et al., 2005) . Asimismo, Chile muestra niveles de integración financiera a la economía global todavía inferiores a las economías avanzadas pero bastante superiores al registro mostrado por las economías emergentes (Banco Central, 2003). Otro indicador relevante del incremento de la participación del sector externo en la economía nacional es el aumento de la significación del intercambio comercial en el producto interno bruto nacional. Mientras en 1997 el intercambio comercial representaba el 18,1\% del PIB, en el año 2005 dicha cifra se alzaba al 26,5\%. El bienio 2004-2005 demuestra el porcentaje de crecimiento más grande en el período.

Cuadro II. Intercambio COMERCIAL DE ChILE EN RELACIÓN A SU PIB

\begin{tabular}{c|c|c|c}
\hline Año & $\begin{array}{c}\text { PIB } \\
\text { (millones de dólares) }\end{array}$ & $\begin{array}{c}\text { Intercambio comercial } \\
\text { (millones de dólares) }\end{array}$ & \% en relación al PIB \\
\hline 1997 & 86.920 & 16.184 & 18,1 \\
\hline 1998 & 89.728 & 15.318 & 17,0 \\
\hline 1999 & 89.046 & 14.340 & 16,1 \\
\hline 2000 & 93.043 & 17.061 & 18,3 \\
\hline 2001 & 96.185 & 16.814 & 17,4 \\
\hline 2002 & 98.286 & 16.196 & 16,4 \\
\hline 2003 & 102.136 & 17.959 & 21,8 \\
\hline 2004 & 108.431 & 23.736 & 26,5 \\
\hline 2005 & 115.314 & 30.636 & \\
\hline
\end{tabular}

Fuente: Banco Central de Chile, varios años.

Otra dimensión de la internacionalización es su participación en foros multilaterales. Uno de los objetivos del primer gobierno de la Concertación fue potenciar la presencia chilena en foros e instancias internacionales, lo que ha sido profundizado en forma especial bajo los tres gobiernos siguientes (Insulza, 1998: 61). A partir de la década de 1990, Chile promovió su participación como miembro de la Comisión de Derechos Humanos de esta institución y ha presidido en una serie de oportunidades el Consejo Económico y Social (ECOSOC). Bajo la última presidencia chilena de este organismo (2002-2004) se impulsaron una serie de iniciativas de promoción del desarrollo social, específicamente para dar seguimiento al Consenso de Monterrey en el marco de los objetivos de desarrollo del milenio. Asimismo, Chile ha sido elegido en dos oportunidades como miembro no permanente del Consejo de Seguridad de las Naciones Unidas (Cuadro III).

3. Los países que preceden a Chile en el ranking son los siguientes: Hong Kong, Singapur, Luxemburgo, Estonia, Irlanda, Nueva Zelanda, Reino Unido, Dinamarca, Islandia y Australia. 


\section{EL CASO DEL MINISTERIO DE RELACIONES EXTERIORES DE CHILE}

\section{CUADRO III. CHILE Y SU PRESENCIA INTERNACIONAL (VÍA ELECCIÓN O DESIGNACIÓN)}

\begin{tabular}{l|l}
\hline $\begin{array}{l}\text { Organización de Naciones Unidas } \\
\text { (ONU) }\end{array}$ & $\begin{array}{l}\text { - Misión permanente de Chile ante Naciones Unidas. Participación en Consejo } \\
\text { de Seguridad de ONU 1990s-2000s (Juan Gabriel Valdés y Heraldo Muñoz) } \\
\text { - Haití. Jefe de misión, Juan Gabriel Valdés 2005-2006 }\end{array}$ \\
\hline $\begin{array}{l}\text { Organización de Estados } \\
\text { Americanos (OEA) }\end{array}$ & Secretario General, José Miguel Insulza 2006-2010 \\
\hline $\begin{array}{l}\text { Organización Internacional del } \\
\text { Trabajo (OIT) }\end{array}$ & Director General, Juan Somavía \\
\hline $\begin{array}{l}\text { Conferencia de Naciones Unidas } \\
\text { para el Comercio y el Desarrollo } \\
\text { (UNCTAD) }\end{array}$ & Vicesecretario General, Carlos Fortín \\
\hline $\begin{array}{l}\text { Comisión Interamericana de } \\
\text { Derechos Humanos }\end{array}$ & Miembro Comisión, José Zalaquett \\
\hline $\begin{array}{l}\text { Corte Interamericana de Derechos } \\
\text { Humanos }\end{array}$ & Jueza Corte, Cecilia Medina \\
\hline $\begin{array}{l}\text { Banco Interamericano de } \\
\text { Desarrollo (BID) }\end{array}$ & Miembro del Directorio Ejecutivo, Alex Foxley \\
\hline $\begin{array}{l}\text { Facultad Latinoamericana de } \\
\text { Ciencias Sociales (FLACSO) }\end{array}$ & Secretario General, Francisco Rojas Aravena \\
\hline $\begin{array}{l}\text { Organismo para la Proscripción de } \\
\text { las Armas Nucleares en América } \\
\text { Latina y el Caribe (OPANAL) }\end{array}$ & Secretario General, Edmundo Vargas Carreño \\
\hline
\end{tabular}

Fuente: Elaboración de FLACSO-Chile en base a documentos oficiales.

La preservación de la paz y el fortalecimiento de la seguridad internacional ha sido un tema especialmente destacado por la Concertación debido a la reciente participación de Chile en el Consejo de Seguridad de las Naciones Unidas. En materia de seguridad, la política exterior de Chile se ha adscrito al concepto de seguridad humana a través de su participación desde 1999 en la Red de Seguridad Humana ${ }^{4}$. Asimismo, Chile activó su participación en operaciones de paz enviando tropas a partir de 1991 a IrakKuwait, El Salvador, Camboya, Bosnia, Kosovo, Chipre y Haití (Tripodi, 2004).

Finalmente, otro de los fenómenos que grafica la mayor apertura de Chile es el explosivo aumento de inmigrantes en Chile donde se produjo una variación muy significativa entre las mediciones del censo de 1982 y 2002, aunque como porcentaje de la población total nacional, todavía Chile se encuentra bajo el nivel que alcanzó en 1960.

\section{Cuadro iV. Personas nacidas en el EXtranjero viviEndo en Chile}

\begin{tabular}{c|c|c|c}
\hline & Extranjeros & Variación intercensal & \% del total población \\
\hline 1960 & 104.853 & 0,94 & 1,42 \\
\hline 1970 & 90.441 & $-13,7$ & 1,02 \\
\hline 1982 & 84.345 & $-6,7$ & 0,75 \\
\hline 1992 & 105.070 & 24,5 & 0,79 \\
\hline 2002 & 184.464 & 75,5 & 1,22 \\
\hline
\end{tabular}

Fuente: MARTÍNEZ (2003).

4. La red está compuesta por trece países: Austria, Canadá, Chile, Grecia, Irlanda, Jordania, Mali, Países Bajos, Noruega, Eslovenia, Sudáfrica, Suiza y Tailandia. 
Desde el punto de vista de la demanda sobre las instituciones del Estado chileno, podemos observar que se ha producido un explosivo aumento de la demanda burocrática sobre el Estado chileno, particularmente a partir de fines de la década de 1990, en lo relativo a solicitudes aprobadas de permisos de residencia temporal, residencia permanente, y nacionalizaciones, incrementándose desde poco más de cinco mil solicitudes en 1985 hasta cerca de cuarenta mil en el año 2003.

\section{EL CONTEXTO DE LA TRANSFORMACIÓN DEL ESTADO}

Si las condiciones internacionales han transformado y generado altas demandas burocráticas, otro factor favorable a una reforma es el discurso y prácticas instaladas en Chile sobre la modernización del aparato público. Las grandes transformaciones en el período 1990-2005 se han referido a la creación de instituciones (Servicio Nacional de la Mujer, Instituto Nacional de la Juventud), la creación de indicadores de gestión e impacto de las políticas públicas, la transformación de instituciones y normas dentro de políticas sectoriales (educación, justicia, salud, infraestructura) y, más recientemente, el cambio de enfoque desde una noción asistencial hacia una centrada en la universalidad de derechos (Waissbluth, 2006).

El proceso de modernización del Estado ha estado marcado por conceptos claves como mejoramiento de la calidad y eficiencia del servicio público, evaluación e incentivos, concursabilidad y profesionalización y gerenciamiento. El paquete de medidas promovido por el gobierno en el año 2003 fue quizás el más relevante impulso hacia la modernización del Estado; contiene iniciativas de transparencia, gestión pública, gestión de recursos humanos, gestión financiera y descentralización.

Algunos hechos llaman la atención de este proceso: primero, cuando se les pregunta a los actores claves del sector privado y público de gobierno y oposición sobre la gestión de relaciones exteriores, existe una muy positiva percepción de la misma (Waissbluth, 2006). Paradójicamente, y como lo observaremos más adelante, cuando se analizan los cambios en materia de gestión dentro del Ministerio de Relaciones Exteriores, todos los cambios que han operado en el Estado desde la transición hasta la fecha han afectado sólo tangencialmente a dicho organismo. Es decir, la positiva evaluación se refiere más a los resultados de política exterior que al proceso de modernización mismo, que de hecho no se ha verificado. Por tratarse de un ministerio con un cuerpo diplomático que actúa bajo un régimen de carrera especial, los procedimientos y mecanismos aplicados a otras instancias del Estado no han funcionado en este caso.

\section{INTERNACIONALIZACIÓN SIN MODERNIZACIÓN}

El incremento de la demanda internacional y las transformaciones del propio Estado intuitivamente podrían implicar un cambio en las lógicas de trabajo institucional para responder a dichos requerimientos de forma más efectiva. Nos referimos a 
una reforma institucional que no significa otra cosa que «cambios deliberados a las estructuras y procesos del sector público para hacer que funcionen mejor en algún sentido» (Waissbluth, 2006).

En esta sección observaremos que las respuestas institucionales no han ido por una «modernización integral» del servicio exterior sino que a través de la creación de instancias de decisión fuera del ámbito burocrático tradicional en lo que denominaremos la creación de una «burocracia técnica paralela». El aumento de demandas ha llevado a las autoridades a fortalecer instancias de apoyo técnico y político sin transformar las estructuras burocráticas existentes. Lo anterior se explica por tres circunstancias: (a) las condiciones políticas que han inhibido abordar una transformación significativa en el ámbito de la Cancillería, (b) la existencia de resistencias corporativas del propio cuerpo diplomático que, pese a que observan la necesidad de una transformación de los incentivos, resisten transformaciones relevantes de los incentivos existentes y (c) el eficiente trabajo de la burocracia tecnocrática que ha sido capaz de responder a las demandas externas.

El Ministerio de Relaciones Exteriores se creó en diciembre de 1871, esto es, 70 años después de producida la independencia. Desde su creación se han verificado muy pocas reformas significativas al mismo (Sánchez y Pereira, 1977). El desarrollo temprano de un Estado burocrático y altamente normado generó una tradición legalista y un estilo civil-pragmático que caracteriza a sus funcionarios ${ }^{5}$. En relación a la primera característica, desde muy temprano en la conformación del ministerio predominó un interés por apegarse a un conjunto de normas que garantizaran, primero un marco territorial que terminó por definirse a comienzos del siglo XX con la firma de acuerdos con los países vecinos y, posteriormente, una serie de iniciativas legales para resguardar tales definiciones. La noción de una política exterior que basa sus orientaciones en el cumplimiento de los tratados y en los principios generales del derecho internacional ha marcado el sentido de tal repartición (Muñoz, 1985; Sánchez y Pereira, 1979).

A esto se agrega un segundo elemento que se refiere a la existencia de «culturas organizacionales» en la Cancillería chilena. Un primer estilo, predominante hasta 1973, se define como «civil-pragmático» y que tiende a reforzar el apego al derecho internacional, el reconocimiento práctico de las realidades de poder mundial, una postura que valora la democracia y se identifica con valores occidentales y el statu quo en materia internacional (Muñoz y Tulchin, 1984; Wilhelmy, 1979 y Colacrai y Lorenzini, 2005) A partir de 1973, dicho estilo dio paso a otro de tipo «pretoriano-ideológico» donde el régimen militar habría impuesto nuevos condicionamientos a la gestión de política exterior incluyendo su propio sello jerárquico y con una visión marcadamente anticomunista del mundo (Muñoz, 1984).

La historia del régimen militar es relevante pues impuso un sello a la Cancillería dado que el control de la política exterior quedó en manos de los uniformados y no del cuerpo diplomático, por lo menos a nivel de ministros y subsecretarios. Hubo intentos,

5. Una discusión sobre el punto en M. Colacrai y M. A. Lorenzini (2005).

6. M. WilHELMY (1979) habla de una subcultura dominante moderada. 
eso sí, de dotar a la Cancillería con capacidades técnicas particularmente en el campo económico durante la breve gestión del canciller Hernán Cubillos (1978-1980), quien produjo un giro parcial hacia visiones que podrían catalogarse dentro de lo que Muñoz denomina como civil-pragmática (Colacrai y Lorenzini, 2005). En términos sintéticos, la experiencia del régimen militar tendió a centralizar las decisiones de la política exterior en las Fuerzas Armadas minimizando el rol del cuerpo diplomático durante gran parte de la dictadura, y hubo una transición desde posturas pragmáticas hacia visiones más ideológicas de las relaciones internacionales.

Esta cultura legalista y pragmática recobró fuerza con el retorno de la democracia en 1990. De hecho, para algunos autores, el pragmatismo de la política exterior chilena ha sido una de las características más persistentes en su historia diplomática (Colacrai y Lorenzini, 2005). El cambio internacional tendía a «desideologizar» los conflictos internacionales al derrumbarse la división este-oeste y al revalorarse la democracia como sistema de gobierno en el hemisferio y en el país. Las tensiones ya no se producirían entre «culturas» competitivas sino que más bien en la forma en que se deberían enfrentar los desafíos internacionales. El discurso político de la Concertación de partidos por la Democracia que asumió el gobierno en 1990 destacaba la necesidad de modernizar la Cancillería. Sin embargo, hasta el año 2006 todos los esfuerzos por realizar transformaciones significativas a la carrera diplomática no se habían concretado. Las tensiones se traducían en cuál sería el papel del cuerpo diplomático en las definiciones de política exterior y el significado que adquiriría la «profesionalización» de la gestión internacional del ministerio.

Desde el punto de vista burocrático, la dotación del Ministerio de Relaciones Exteriores no sufrió mayores cambios sino hasta el segundo año del gobierno de Ricardo Lagos. En términos absolutos, se produjo un incremento de la planta de un 18\% si se compara el año 2004 con 1995. No obstante, cuando se observa la evolución de la planta administrativa del conjunto del Estado, observamos que la planta de 2004 representa a un porcentaje ligeramente inferior que lo que representaba en 1995.

Cuadro v. Ministerio de Relaciones Exteriores. Dotación 1995-2004

\begin{tabular}{c|c|c}
\hline Año & $\begin{array}{c}\text { Dotación Ministerio } \\
\text { Relaciones Exteriores }\end{array}$ & Dotación como \% del sector público \\
\hline 1995 & 1.208 & $0,92 \%$ \\
\hline 1996 & 1.265 & $0,96 \%$ \\
\hline 1997 & 1.252 & $0,94 \%$ \\
\hline 1998 & 1.248 & $0,92 \%$ \\
\hline 1999 & 1.252 & $0,91 \%$ \\
\hline 2000 & 1.240 & $0,86 \%$ \\
\hline 2001 & 1.307 & $0,87 \%$ \\
\hline 2002 & 1.441 & $0,94 \%$ \\
\hline 2003 & 1.468 & $0,93 \%$ \\
\hline 2004 & 1.430 & $0,89 \%$ \\
\hline
\end{tabular}

Fuente: Ministerio de Hacienda de Chile. Dotación efectiva de personal civil del Gobierno Central. www. hacienda.cl. 
Un dato interesante de observar es la proporción del personal de planta y con contratos parciales. Lo que el cuadro siguiente indica es que las dotaciones de planta y a contrata en el Ministerio de Relaciones Exteriores, proporcionalmente, se han reducido en 10 puntos entre los años 2000 y 2005. La diferencia se explica por un incremento en el personal que trabaja en reparticiones dependientes del ministerio pero que gozan de cierta autonomía, como la Dirección General de Relaciones Económicas Internacionales (DIRECON), el Instituto Antártico y la Dirección de Fronteras.

CuAdro VI. Dotaciones DESAGREGADAS POR AÑO. SECRETARÍA DE AdMINISTRACIÓN GENERAL y SERVICIO EXTERIOR

\begin{tabular}{c|c|c|c|c|c}
\hline Año & Total & $\begin{array}{c}\% \text { del total } \\
\text { MINREL }\end{array}$ & $\begin{array}{c}\% \\
\text { planta }\end{array}$ & $\begin{array}{c}\% \\
\text { contrata }\end{array}$ & $\begin{array}{c}\% \\
\text { honorarios }\end{array}$ \\
\hline 2000 & 1.014 & 81,7 & 83 & 17 & - \\
\hline 2001 & 1.021 & 78,1 & 85 & 15 & - \\
\hline 2002 & 1.014 & 70,3 & 85 & 15 & - \\
\hline 2003 & 1.022 & 69,1 & 83 & 17 & - \\
\hline 2004 & 1.022 & 71,4 & 82 & 18 & - \\
\hline 2005 & 992 & ND & 83 & 17 & - \\
\hline
\end{tabular}

Se excluyen Dirección Económica (DIRECON), Dirección de Fronteras (DIFROL), Instituto Antártico y Agencia de Cooperación Internacional (AGCI) integrada en 2005 al ministerio.

Fuente: Balance de Gestión integral, Ministerio de Relaciones Exteriores 2000 al 2005. En www.hacienda.cl.

El fenómeno más interesante se ha producido en la DIRECON que vio incrementada su dotación de 98 a 281 funcionarios entre el año 2000 y 2005 . El incremento más significativo se ha dado por la modalidad de funcionarios a contrata que de representar el 16\% de dicha repartición en el año 2000 pasaron a representar el $84 \%$ en el año 2005. La mayor parte de estos funcionarios son profesionales del área de la economía y del derecho.

CUADRO VII. DOTACIONES DESAGREGADAS POR AÑO.

DiRECCIÓN GENERAL DE RELACIONES ECONÓMICAS INTERNACIONALES

\begin{tabular}{c|c|c|c|c|c}
\hline Año & $\begin{array}{c}\text { Total } \\
\text { DIRECON }\end{array}$ & $\begin{array}{c}\% \text { del total } \\
\text { MINREL }\end{array}$ & $\begin{array}{c}\% \\
\text { planta }\end{array}$ & $\begin{array}{c}\% \\
\text { contrata }\end{array}$ & $\begin{array}{c}\% \\
\text { honorarios }\end{array}$ \\
\hline 2000 & 98 & 7,9 & 84 & 16 & - \\
\hline 2001 & 162 & 12,4 & 58 & 42 & - \\
\hline 2002 & 351 & 24,3 & 32 & 68 & - \\
\hline 2003 & 362 & 24,6 & 31 & 69 & - \\
\hline 2004 & 318 & 22,2 & 35 & 65 & - \\
\hline 2005 & 281 & ND & 16 & 84 & - \\
\hline
\end{tabular}

Fuente: Balance de Gestión integral, Ministerio de Relaciones Exteriores 2000 al 2005. En www.hacienda.cl. 
Lo anterior es coincidente con el incremento en los recursos para el Ministerio de Relaciones Exteriores en igual período. Entre 1990 y 2003, se produjo un incremento promedio del presupuesto de dicho ministerio de 8,6\%. Entre 2000 y 2003, los gastos de la Secretaría de Administración General y Servicio Exterior se explican por un mayor desembolso, no en la planta de personal que no sufrió grandes variaciones, sino que de las remuneraciones variables, esto es, contratos por prestación de servicios en honorarios (Instituto Libertad y Desarrollo, 2003).

Lo que estas cifras demuestran es que, pese a una mayor demanda producto de la internacionalización del país, la estructura burocrática ha tendido a crecer en términos absolutos aunque no en términos relativos, es decir, el crecimiento de la burocracia de la Cancillería no es equivalente al crecimiento de otros sectores del Estado. En segundo lugar, dentro del ministerio se observa una importante estabilidad hasta 1999 y una transformación significativa a partir del año 2001. Esto coincide con el crecimiento de las demandas a partir de la firma de acuerdos de libre comercio con diversos países en la década de los 2000. En tercer término, la modalidad escogida ha sido mediante el aumento de personal profesional vía «contrata» y no un crecimiento de las plantas administrativas del ministerio. Esto se explica en gran medida por los propios incentivos existentes en la actualidad en la administración del presupuesto, que inhiben al Ejecutivo ampliar plantas sin una correspondiente modificación de los presupuestos que anualmente se discuten en el Congreso. En síntesis, las autoridades de gobierno han respondido al aumento de una demanda internacional vía la creación de una burocracia «técnica paralela».

La última modificación normativa significativa se hizo durante el régimen militar en 1978 (Decreto con Fuerza de Ley 178) que definió misiones y algunas funciones de la misma. Entre 1990 y 2006, se han realizado cambios mínimos como la ampliación de la planta del servicio exterior que tuvo por objetivo incorporar ex funcionarios que fueron alejados de sus cargos durante el régimen militar (Ley 19.115), se estableció un reglamento nuevo de calificaciones del personal (1992), la modernización del sistema consular chileno (1998) y, en los años 1996 y 2005, se establecieron comisiones que discutieron la modernización del ministerio sin esto terminar en algún proyecto o reforma concretos.

El diagnóstico político generalizado entre partidos de oposición, gobierno y dentro de la propia corporación de diplomáticos de carrera, que se vio expresado en un proceso de audiencias públicas realizadas por el ministerio en 2005, planteó que se requerían cambios en la estructura organizacional, en materia de recursos humanos, para mejorar las condiciones de trabajo de los profesionales diplomáticos ${ }^{7}$, de incentivos profesionales, de coordinación interministerial y de coordinación entre el mundo privado y el público. Por ejemplo, el ex ministro de Relaciones Exteriores del régimen militar Hernán Felipe Errázuriz sostenía en 2005 que no sólo era necesaria una reforma a la

7. Hacia 2005 el total de diplomáticos de carrera sumaba aproximadamente 300 , de los cuales 100 eran abogados, 43 licenciados en diferentes áreas, 35 ingenieros, 31 administradores públicos, 36 profesores de Estado, 18 periodistas, entre otros. 
ley orgánica en cuanto a funciones, atribuciones, estructura y personal, sino que también y

[...] más urgente que un nuevo estatuto legal la modernización de la cancillería supone la introducción de criterios y prácticas modernas de gestión, que no son de rango legal y que son determinantes para su eficacia.

\section{Agregaba que}

[...] hay consenso sobre la falta de agilidad, debilitamiento del profesionalismo, politización operativa, anacronismo de algunos procedimientos, imperfecciones en los procesos de toma de decisiones, fallas organizativas y administrativas [...]. A la vez, la modernización de la cancillería debe integrarse a la modernización del aparato estatal y del servicio civil, y no puede ser independiente de estas reformas, también pendientes (Errázuriz, 2005).

Por su parte, los funcionarios de la carrera diplomática agrupados en la Asociación de Diplomáticos de Carrera (ADICA) sostenían que ya en 1995 proponían al Ministerio de Relaciones Exteriores un plan de perfeccionamiento integral del ministerio: «Nuestra disposición al cambio y la promoción de una reforma profunda de nuestra cancillería ha sido una constante durante los últimos 15 años» (ADICA, 2005).

Para el ex diputado de la Democracia Cristiana y encargado del área internacional de su partido Tomás Jocelyn Holt resultaba imperiosa una reforma a la Cancillería. A su juicio, se requería un «servicio exterior flexible, profesional y especializado supeditado a una estrategia que promueva a Chile como un buen partner y socio confiable» (Jocelyn Holt, 2005). Por su parte, el ex director de Planificación de la Cancillería y actual diputado del Partido Socialista sostenía que se requería una reforma que considerara los principios de flexibilidad, coordinación, participación, descentralización, profesionalización y especialización ${ }^{8}$.

\section{LOS FACTORES QUE INHIBEN EL CAMBIO}

Tres factores complementarios explican esta ausencia de cambios orgánicos significativos?: el primero se refiere a las condiciones políticas domésticas poco favorables para concretar las promesas de reforma. La segunda explicación se centra en la existencia de dos visiones polares sobre el sentido que debiera tener una «modernización» que inhiben la construcción de un consenso interno. Se advierten dos modelos competitivos de «profesionalización» que no han logrado consensuarse políticamente al interior de la Cancillería. Finalmente, la tercera explicación se refiere al eficiente

8. «La reforma de la Cancillería». Columna del diputado Marcelo Díaz. El Mostrador, 5 de mayo de 2006.

9. Estos factores son desarrollados con mayor detenimiento en C. FuENTES (2007). 
desenvolvimiento de una burocracia paralela que ha funcionado en el ministerio para responder a la internacionalización económica del país. Esta forma de decidir se ha extendido incluso hacia esferas políticas de alto nivel, donde la diplomacia paralela se transforma en más relevante que los conductos regulares de funcionamiento de la Cancillería.

\section{V.1. El contexto político}

La modernización de la Cancillería alude a una serie de transformaciones en la estructura organizativa, los recursos humanos y los incentivos existentes en tal repartición. Ello implicaría por una parte la necesidad de reformar la Ley Orgánica del Ministerio, lo que requeriría un amplio consenso político, o al menos el apoyo de uno de los partidos de oposición. Por lo tanto, una primera condicionante política es la necesidad de contar con los votos suficientes en el Congreso para aprobar una reforma significativa.

Desde el punto de vista de la oposición, uno de los puntos más significativos de su agenda ha sido reducir la injerencia del gobierno en la designación de embajadores, ampliando la posibilidad de que funcionarios de carrera ocupen cargos clave en el ministerio. En cada cambio de gobierno, la oposición ha demandado del gobierno una mayor «profesionalización» de la Cancillería vía la reducción de la designación de embajadores políticos. Esta demanda es compartida por la ADICA, lo que sin duda ha dificultado el diálogo con el gobierno.

Pero adicionalmente, desde el punto de vista político, existe una disonancia entre el alto costo político de la reforma y la opacidad de sus beneficios. Es decir, el costo político de asumir una reforma de esta naturaleza es alto por cuanto implicaría para el gobierno aceptar una serie de condiciones de la oposición en lo relativo a designación de cargos políticos en embajadas. Además, la reforma implicaría al menos en un primer momento un incremento de recursos para realizar la transformación, lo que generalmente no es bien visto por la opinión pública. Por otra parte, los potenciales beneficios de tal reforma no serían observados por la opinión pública dado que no se traduciría en un beneficio inmediato, como sí ocurre con reformas como al sistema de salud, justicia o pensiones. La opacidad de los beneficios desincentiva a las autoridades políticas a asumir una batalla política de inciertos resultados. A ello debe agregarse que la política exterior nunca ha figurado entre las principales preocupaciones de la población ${ }^{10}$.

Finalmente, y también desde el punto de vista político, el timing electoral tampoco ayuda a que se concretice una reforma integral. La existencia en Chile de elecciones en forma relativamente frecuente genera un fuerte desincentivo para que las autoridades inicien procesos de cambio estructural, salvo cuando se perciban beneficios políticos inmediatos, que como ya señalamos no es el caso de la política internacional.

10. En la Encuesta Nacional del CEP, los temas de política exterior no figuran como una preocupación de la ciudadanía (ver http://www.cepchile.cl/encuestas). 
Aunque con la reforma constitucional de 2005 se ordenaron algunas de las elecciones, se decidió acortar el período presidencial de 6 a 4 años, lo que redujo las posibilidades de implementar políticas públicas de difícil aprobación en el Congreso. Adicionalmente, en el año 2008 se darán elecciones municipales, por lo que las autoridades del nuevo gobierno contarán en términos prácticos con los años 2006 y 2007 para desarrollar una agenda legislativa de cambios institucionales significativos.

\section{CuAdro viII. Timing ELECTORAL EN ChILE}

\begin{tabular}{c|c|c|c|c|c|c|c|c|c}
\hline 1993 & 1996 & 1997 & 1999 & 2000 & 2001 & 2004 & 2005 & 2008 & 2009 \\
\hline $\begin{array}{c}\text { Presidente } \\
\text { Congreso }\end{array}$ & Mun. & Congreso & Presidente & & Congreso & & $\begin{array}{c}\text { Presidente } \\
\text { Congreso }\end{array}$ & & $\begin{array}{c}\text { Presidente } \\
\text { Congreso } \\
\text { Mun. }\end{array}$ \\
\hline
\end{tabular}

Fuente: www.elecciones.cl. Mun = Municipal.

\section{V.2. Los alcances y sentidos discrepantes de la profesionalización}

Si las condiciones políticas no ayudan a motivar una reforma, los alcances y sentidos discrepantes de la profesionalización han debilitado aún más las posibilidades de lograr un consenso básico sobre la misma. En relación a los alcances, en las propuestas de reforma iniciadas desde el gobierno (1996, 1998 y 2005) se pusieron objetivos ambiciosos de reforma y que consideraban al menos tres objetivos: primero, una reforma organizacional con el objetivo de racionalizar y homologar el trabajo de las diversas direcciones. Ello implicaba, por ejemplo, la idea de sustituir el esquema actual de una subsecretaría, mediante la creación de subsecretarías de relaciones económicas, de asuntos políticos y de asuntos administrativos. Segundo, la idea de transformar los mecanismos de evaluación a fin de introducir incentivos al mérito, reduciendo la importancia relativa de la experiencia. Tercero, reevaluar la situación económica de los funcionarios de carrera a fin de generar incentivos para la permanencia en Santiago y promover determinadas destinaciones ajustándolas a los niveles de responsabilidadriesgo. Cuarto, promover una reforma en el sistema de enseñanza para diplomáticos que, en la actualidad, se realiza a través de la Academia Diplomática. La extensa agenda de reformas, a juicio de los mismos diplomáticos, ha generado objetivos demasiado ambiciosos y que en la práctica afectan tantos intereses que son irrealizables ${ }^{11}$.

Pero, adicionalmente, los actores involucrados en el debate sostienen visiones opuestas sobre el significado de lo que es la «modernización» de la Cancillería. Podríamos definir dos visiones «polares» del sentido que podría orientar una reforma. Un primer significado es de «profesionalización abierta», esto es, una concepción que destaca la meritocracia como una condición fundamental para la gestión moderna y eficiente del Estado. En esta concepción se destacan los incentivos o premios a los logros de objetivos y a la innovación como una parte esencial de la labor de los funcionarios.

11. Grupo de discusión conducida por el autor con funcionarios de carrera. Enero de 2007. 
Lo anterior implica la generación de mecanismos objetivos de evaluación por desempeño y concursabilidad de cargos como instrumento de acceso a cargos de relevancia.

Se trata de una visión donde la organización es concebida en términos más horizontales que verticales. Los privilegios tienden a ser acotados y a concentrarse en ámbitos especializados con el fin de retener a funcionarios que se verían tentados a abandonar sus cargos por ofertas en el mercado laboral. El vínculo político requiere ser de alto nivel pero de carácter profesionalizante. En otros términos, en una concepción de profesionalización abierta, los vínculos políticos o sectoriales (con el mundo privado, por ejemplo) podrían llegar a ser una buena condición de un funcionario de alto rango, siempre y cuando no interfiera en su desempeño profesional. La noción de un político con altas capacidades técnicas (o un técnico con una alta visión política) en determinadas circunstancias es clave para el éxito en una gestión internacional.

En el otro lado de la balanza, encontramos una concepción de «profesionalización cerrada», esto es, una noción que privilegia la antigüedad por sobre el mérito bajo la concepción de que la experiencia diplomática es una condición crucial para el desenvolvimiento de un buen diplomático. El mérito es considerado dentro de una estructura de incentivos que pondera tanto las capacidades individuales como la antigüedad en la función. Esta noción tiende a privilegiar una concepción jerárquica o vertical de la organización. Los privilegios se darían por antigüedad y se aspira a una total insularidad o autonomía respecto de una potencial influencia política. Al considerarse la función diplomática como particular y altamente especializada, se pretende obtener una profesionalización a partir de la no injerencia política en las designaciones. La antigüedad y el mérito (en ese orden) serían los factores determinantes en quién ocupa posiciones en la escala jerárquica. Idealmente, la función diplomática debe ser ejercida por diplomáticos.

CUADRO IX. DOS VISIONES POLARES DE LA «PROFESIONALIZACIÓN»

\begin{tabular}{l|c|c}
\hline Meritocracia & $\begin{array}{c}\text { Profesionalización } \\
\text { «abierta» }\end{array}$ & $\begin{array}{c}\text { Profesionalización } \\
\text { «cerrada» }\end{array}$ \\
\hline Organización & $\begin{array}{c}\text { Incentivos al mérito } \\
\text { Conación por desempeño } \\
\text { Concursabilidad }\end{array}$ & Incentivos al mérito, respetando antigüedad \\
\hline Privilegios & Horizontal & Jerárquica \\
\hline Vínculo político & Específicos y por especialización & Incentivos antigüedad \\
\hline
\end{tabular}

Fuente: Elaborado por el autor a partir de BID (2006) y MinTZBERG, QUINN y VOYER (1997).

En el caso de la reforma a la Cancillería precisamente estos dos modelos están en disputa. En los últimos tres años se ha producido un acercamiento de posturas donde algunos actores políticos y del cuerpo diplomático han destacado puntos de consenso como son el mayor énfasis en la meritocracia y el fortalecimiento de las capacidades de innovación de los funcionarios públicos. Al evidenciarse el crecimiento de una «diplomacia paralela», particularmente en el caso de la DIRECON, se han incrementado 
los incentivos para establecer un acuerdo sobre una necesaria modernización. No obstante, la tensión entre un modelo y otro aún se mantiene.

Las diferencias se hacen patentes cuando se contrasta la agenda y énfasis de uno y otro sector. Por ejemplo, el gobierno decidió concursar el puesto de director de Administración del Ministerio de Relaciones Exteriores, cargo que fue ocupado por un connotado político, ingeniero comercial y economista del partido demócrata cristiano, Pablo Piñera. Su experiencia en puestos de función pública reflejan el sentido de una concepción de profesionalización «abierta» dado que se trata de un cargo que se decide concursar y donde se escogió a alguien que si bien tiene una historia política evidente, también tiene amplios créditos técnicos para desempeñarse en dicha función ${ }^{12}$.

La respuesta de la Asociación de Diplomáticos representa el sentido de una «profesionalización cerrada». Para la ADICA, la función de la Dirección de Administración debiera ser ocupada por «el jefe administrativo del servicio, tener 20 años a lo menos en la planta del servicio exterior y el título profesional afín con la función» (ADICA, 2005).

Otros casos grafican esta diferencia. Para los diplomáticos se requerirían mecanismos de control sobre las embajadas a partir de un «inspector de embajadas», un funcionario de carrera (y no externo al servicio) que vele por el cumplimiento de las funciones dentro de las embajadas y atienda los problemas específicos de ella. La noción de modernización que la asociación de diplomáticos asume se sintetiza en una agenda más bien de carácter corporativo. Para la ADICA, la meritocracia se busca promover dentro del sistema. Un ejemplo patente de esta noción es la aceptación de «consultores» externos que, a juicio de los diplomáticos, deben estar guiados por un escalafón a ser incorporados por concurso y en base a antecedentes objetivos: «en este escalafón deben incluirse a aquellos funcionarios del Servicio Exterior que pierdan por tercera vez los concursos de ascensos o que permanezcan en el mismo grado por más de doce años» (ADICA, 2005). En otros términos, se busca garantizar la no salida de funcionarios de carrera, al margen de la evaluación que se haga de ellos.

La percepción generalizada de los funcionarios asociados a ADICA responde al ideal de «profesionalización cerrada». Una encuesta conducida recientemente es indicativa de este fenómeno. Entre los principales aspectos negativos mencionados por los funcionarios figura como segundo problema de la Cancillería luego de la poca coordinación $(21,8 \%)$, la existencia de directores ajenos a la carrera (18,8\%). Adicionalmente, los funcionarios de carrera señalan la injerencia de los intereses político-partidistas (38,0\% de referencias), el amiguismo (36,3\%) y el uso de influencias $(28,7 \%$ ) y el tener «padrinos» políticos $(14,6 \%)$ como los tres principales aspectos que inciden en sus

12. Pablo Piñera es ingeniero comercial y tiene un máster en economía en la Universidad de Boston. Ha sido subsecretario de Hacienda, consejero del Banco Central, director ejecutivo de Televisión Nacional de Chile, director de contabilidad y finanzas del Ministerio de Obras Públicas y subsecretario de Obras Públicas. 
evaluaciones, marcando una distancia respecto de los aspectos que deberían ser considerados y que analizaremos más abajo ${ }^{13}$.

Existe, sin embargo, una tensión entre la necesidad de una «profesionalización cerrada» (exenta de influencias internas), y el desarrollar un mecanismo que premie el mérito por sobre un sistema jerárquico. Cuando se le consulta a los entrevistados sobre aspectos que influyen favorablemente en la evaluación de funcionarios, los tres aspectos con mayores menciones son la experiencia $(26,8 \%)$, la iniciativa $(24 \%)$ y el cumplimiento de objetivos laborales $(19,3 \%)$. Cuando se pregunta qué aspectos deberían influir favorablemente en la evaluación de funcionarios, los tres aspectos con mayores menciones, son: el cumplimiento de objetivos laborales $(82,5 \%)$, la iniciativa $(80,7 \%)$, el manejo de idiomas $(66,7 \%)$ y la experiencia $(64,9 \%)$ (ADICA, 2006). Es decir, claramente predominan valores meritocráticos sobre los relativos a la experiencia o jerarquía. Por otra parte, el 49,7\% de los entrevistados sostienen que mostrar iniciativa en el desempeño profesional es beneficioso. Al respecto, las políticas de carrera peor evaluadas por los funcionarios de carrera en la misma encuesta corresponden a las calificaciones anuales, las políticas de retiro y jubilaciones y los ascensos, demostrando de nuevo una preocupación por el ascenso y la meritocracia dentro de la carrera ${ }^{14}$.

Lo anterior es consistente con la preocupación demostrada por funcionarios de carrera en entrevistas personales y grupales ${ }^{15}$. Cuando se preguntó sobre las principales prioridades de reforma del ministerio en el futuro inmediato, se mencionó repetidamente la necesidad de establecer un mecanismo transparente de evaluación funcionaria, vinculando los estímulos monetarios y simbólicos con el mérito demostrado por los funcionarios:

[...] una evaluación transparente y objetivada podría ser muy positiva para estimular a los funcionarios. No puede ser que el $100 \%$ de los funcionarios esté en la máxima categoría de evaluación todos los años ${ }^{16}$.

En síntesis, la existencia de dos modelos de «profesionalización» ha inhibido el avanzar en un proyecto consensuado. La apertura hacia la competencia y a la meritocracia es sin duda el gran punto en conflicto en esta reforma. En la medida en que la coalición de gobierno promueve tal política ya sea en la designación de embajadores y/o

13. Encuesta de ADICA a funcionarios de carrera. Se envió la encuesta a los 282 funcionarios de carrera, respondiendo 171 de ellos (41,7\%). Encuesta realizada entre junio y agosto de 2006 (ADICA, 2006).

14. En una escala de 1 a 7 siendo 1 pésimo y 7 excelente, el porcentaje de personas que evaluó de 1 a 3 las siguientes políticas fueron: 93,5\% calificaciones, 88,6\% retiro y jubilaciones, 91\% los ascensos, $53,8 \%$ la formación y el perfeccionamiento y $57,7 \%$ las destinaciones.

15. Se sostuvieron entrevistas con funcionarios de carrera entre los meses de septiembre de 2006 y enero de 2007. Adicionalmente, se utilizó una técnica de grupo de discusión en el mes de enero de 2007 a fin de contrastar los resultados de las entrevistas individuales. Se organizaron dos grupos de discusión con funcionarios de alto rango y rango medio, utilizando una pauta de discusión y una encuesta estructurada. Los resultados de estos grupos de discusión en C. FUENTES (2007).

16. Intervención de funcionario de carrera en grupo de discusión. Enero de 2007. 
altos puestos en la administración central de la Cancillería, se generan resistencias corporativas significativas de parte de los funcionarios de carrera. Usualmente, esta apertura se traduce en mayores niveles de politización al no existir un procedimiento adecuado para concursar cargos de significación. Pero incluso en los cargos que han comenzado a ser concursados (el de la Dirección Administrativa fue la primera experiencia de su tipo en dicha repartición), al depender la definición de los actores políticos, sigue existiendo una percepción de «politización» en las nuevas modalidades buscadas.

\section{V.3. La eficiente respuesta de algunas reparticiones (el caso de la DIRECON)}

Otro factor que ha inhibido el avance de una reforma es, paradójicamente, la buena gestión alcanzada a través del establecimiento de una diplomacia «paralela» como es el caso de la DIRECON. Esta repartición fue creada mediante el Decreto con Fuerza de Ley número 53, del año 1979. Su creación respondió al objetivo de fortalecer el papel económico de la política exterior, frente al modelo económico imperante y la necesidad de apertura. Durante la transición democrática, esta dirección se transformó en un órgano técnico fundamental para la negociación e implementación de acuerdos comerciales que han acompañado la estrategia de regionalismo abierto en las relaciones económicas internacionales de Chile.

Esta dirección tiene por funciones, entre otras: colaborar, dentro del contexto de la política económica que fije el gobierno, al desarrollo de las exportaciones del país; orientar la asistencia económica y financiera proveniente del exterior; intervenir en todo lo atinente a los grupos de trabajo, negociaciones bilaterales y multilaterales y demás comisiones internacionales mixtas en que participe Chile; estudiar en todos sus aspectos la participación de Chile en el comercio internacional y proponer las medidas pertinentes, las que deberán contar con la conformidad escrita del ministro de Hacienda; organizar misiones públicas y privadas al exterior. Asimismo, se orienta a promover la visita de misiones comerciales extranjeras, auxiliares en la programación de sus actividades y atenderlas durante su permanencia en el país; y promover y negociar tratados y demás acuerdos internacionales de carácter económico, los que también deberán tener la conformidad escrita del ministro de Hacienda.

Tal como se indicó anteriormente, la DIRECON ha cobrado una gran relevancia política y técnica al ser la dirección que ha conducido las negociaciones internacionales. Ello se ha concretado a partir del fortalecimiento de sus equipos técnicos y del fortalecimiento de una diplomacia paralela que no necesariamente pasa por la diplomacia tradicional. A juicio del anterior director, Osvaldo Rosales, se trata de una organización atípica por cuanto tiene un alto sesgo profesional, con muy baja participación de funcionarios de carrera. Las actividades de coordinación DIRECON se han desarrollado de manera informal, generando vínculos no institucionales pero crecientemente formalizados con el sector privado. No se llegó a concretar una mesa técnica de trabajo pero sí se avanzó en rondas de información y consulta con los principales gremios 
empresariales del país. En cuanto a la coordinación interministerial, se estableció un comité interministerial que se reunía periódicamente para ver el avance de las negociaciones y un equipo técnico donde participaba Hacienda, Economía, Agricultura y la Secretaría General de la Presidencia ${ }^{17}$.

La DIRECON tiene la particularidad de establecer vínculos de coordinación de alto nivel, por la singularidad de las acciones y políticas en el ámbito de la política exterior, pero carecer de vínculos estrechos de mediano y bajo nivel con la Cancillería. Por ejemplo, para el director de Estudios de DIRECON, se carece precisamente de información del nivel político para mejorar los estudios o una mejor coordinación con otras reparticiones del Estado para mejorar la calidad de la información que se entrega a los tomadores de decisión. Los vínculos con la diplomacia tradicional tienden a ser débiles y a estar mediados por el estrato superior de dicha repartición o tienden a ser informales y ocasionales. Las mayores vinculaciones se dan con el Ministerio de Hacienda y Economía $^{18}$. La misma percepción tiene la jefa del área de desarrollo estratégico de ProChile (instancia dependiente de DIRECON), dado que enfatiza que los mayores contactos son dentro de la repartición con el área de negociaciones y con la Agencia de Cooperación Internacional, «con el resto de la Cancillería no nos relacionamos» ${ }^{19}$.

Este modelo ha generado tensiones internas dentro de la burocracia de la propia Cancillería dado que se produce una diferenciación de estatus entre los profesionales del área económica y el resto de los funcionarios. De acuerdo a algunos funcionarios, uno de los principales desafíos de la Cancillería es internalizar los temas de economía internacional por cuanto generan desigualdades que se expresan en las prioridades que las autoridades políticas le otorgan a dicha repartición, las desigualdades de sueldos entre funcionarios de similar grado, y las diferencias que en este terreno se producen entre aquellos que tienen responsabilidad diplomática y los que abordan cuestiones económicas $^{20}$.

\section{CONCLUSIONES}

En este artículo hemos dado cuenta de las respuestas institucionales a la internacionalización de Chile. Se sostiene que dada la existencia de condiciones políticas e intereses burocráticos predefinidos, se hace muy difícil avanzar en una reforma sustantiva a un sector clave para el país: el Ministerio de Relaciones Exteriores. La existencia de una estructura burocrática tradicional y que históricamente ha contado con altos niveles de autonomía hacen difícil pensar en un cambio.

17. Entrevista a Osvaldo Rosales, director de DIRECON (2000-2004), 6 de abril de 2006.

18. Entrevista con Alexis Guardia, jefe del Área de Estudios de DIRECON, 23 de agosto de 2006.

19. Entrevista con Lorena Sepúlveda, jefa del Área de Desarrollo Estratégico, Pro-Chile, 23 de agosto de 2006.

20. Grupo de discusión con funcionarios de carrera. Enero de 2007. 
Se sostiene que existen tres razones que han inhibido una reforma: el contexto de intereses políticos y el timing asociado a la coyuntura política, el alcance y sentido que adquiere la reforma de la Cancillería cada vez que se ha planteado y la existencia de mecanismos alternativos para avanzar políticas institucionales en dicho sector. Tal como un ex funcionario lo expresó vívidamente «al principio del gobierno (Lagos 2000-2006) quisimos realizar cambios administrativos, pero el costo y energía a invertir era tal que decidimos concentrarnos en los resultados políticos más inmediatos, es decir, firmar acuerdos» $»^{21}$.

Existe un espacio de consenso político amplio para abordar una reforma basada en cuestiones de meritocracia, especialización e incentivos a la competencia. Sin embargo, el significado de la profesionalización adquiere sentidos muy diferentes y que esencialmente tienen que ver con el grado de autonomía respecto de los actores políticos y los mecanismos que definen tal profesionalización. Es muy probable que el debate en Chile sobre la gerencia pública impacte positivamente al Ministerio de Relaciones Exteriores al generar mecanismos institucionales para la selección de determinados puestos claves en dicho sector del Estado. Sin embargo, lo que ha sido un factor importante de cambio en la mayor parte de la administración pública en Chile se ha constituido en un obstáculo en la Cancillería en la medida en que no se avanza en un esquema renovado de incentivos a la carrera. El resultado del statu quo se debe, en parte, a la ausencia de alternativas de política definidas y que susciten consenso político fuera y dentro de la Cancillería. Todos saben que se requiere hacer algo, pero, al existir distintos modelos de desarrollo, se alcanza un resultado subóptimo del statu quo.

El trabajo incorpora algunas luces sobre los factores inhibidores del cambio institucional. Se requerirían más estudios comparativos para entender los factores que posibilitan la reforma en algunos casos (el Poder Judicial en América Latina por ejemplo) y en otros no. ¿Bajo qué condiciones fue posible una reforma al sector de justicia y cuáles de estas condiciones se cumplen o no en el caso de la Cancillería? Análisis comparados permitirían mejorar nuestro entendimiento sobre procesos de reforma del Estado en Chile y América Latina.

\section{BIBLIOGRAFÍA}

ADICA. Hacia una Cancillería para el siglo XXI. Ideas generales de ADICA sobre modernización integral del Ministerio de Relaciones Exteriores, 2005. En [www.adica.cl].

- Estudio de mercado. Situación del Servicio Exterior. Santiago: ADICA, octubre de 2006.

Banco Central De Chile. Análisis del balance externo de Chile. Economic Policy Papers, 2003. Santiago: Banco Central de Chile.

Banco InTERAmericano De DesarRollo. La política de las políticas públicas. BID, David Rockefeller Center for Latin American Studies, Harvard University, 2005.

21. Entrevista con funcionario del Ministerio de Relaciones Exteriores. Junio de 2006. 
EL CASO DEL MINISTERIO DE RELACIONES EXTERIORES DE CHILE

ColaCRAI, Myriam y LoRENZINI, M. A. La política exterior de Chile: ¿Excepcionalidad o continuidad? Una lectura combinada de fuerzas profundas y tendencias. Confines, 2005, vol. 1, agosto-diciembre.

EgAÑA, Rodrigo. Reforma y modernización del Estado en Chile: avances y desafíos. Documento de trabajo n..$^{\circ}$ 340. Santiago: Centro de Estudios Públicos, 2002.

ERRÁzURIZ, Hernán. Modernización de la Cancillería, 2005. En [www.adica.cl].

FuENTES, Claudio. Adaptación organizacional sin modernización: el caso de la Cancillería Chilena. Informe de Investigación FONDECYT. Mimeo. Santiago, 2007.

Instituto LiberTAD y DesarRollo. Relaciones Exteriores crece y crece, 2003. En [http://www. lyd.com/programas/economico/presupuesto2004/relaciones.html].

InsulZA, José Miguel. Ensayos sobre política exterior de Chile. Santiago: Editorial Los Andes, 1998. Jocelyn HolT, Tomás. Presentación de la Democracia Cristiana ante el Grupo de Trabajo Cancillería Siglo XXI. Santiago: Academia diplomática, 2005. En [www.adica.cl].

MARCEL, Mario. Las opciones para la reforma del Estado en Chile. En VALDÉs, Salvador Prieto (ed.). Reforma del Estado. Dirección pública y compras públicas (vol. II). Santiago: Centro de Estudios Públicos, 2002.

MARTínEZ, Jorge. Breve examen de la inmigración en Chile según datos generales del Censo de 2002. Documento de Trabajo n. ${ }^{\circ}$ 3. Santiago: Organización Internacional de las Migraciones, 2003.

MiLes, Marc A. et al. Index of Economic Freedom. The Link Between Economic Opportunity and Prosperity. Washington DC: Heritage Foundation, 2005.

MintzBerg, H.; Brian, J. y Voyer, J. El proceso Estratégico. Conceptos, contextos y casos. México: Pearson Educación, 1997.

MuÑOZ, Heraldo. La política exterior de Chile: la crisis continúa. En MuÑoz, Heraldo (comp.). Anuario de Politicas Exteriores Latinoamericanas. Las politicas exteriores latinoamericanas frente a las crisis. Buenos Aires: GEL-PROSPEL-CERC, 1985.

MuÑOZ, Heraldo y TulCHIN, Joseph. Entre la autonomía y la subordinación: Política exterior de los países latinoamericanos. Buenos Aires: GEL Editores, 1984.

ROMERO, Sergio. Cancillería del siglo XXI, 2005. En [www.adica.cl].

SÁNCHEZ, Walter y PEREIRA, T. 150 años de política exterior chilena. Santiago: Editorial Universitaria, 1977.

TRIPODI, Paolo. La misión de Haití desde la mantención hasta la imposición de la paz: Nuevos desafíos para los cascos azules chilenos. Revista Fuerzas Armadas y Sociedad, 2004, año 18, vol. 1-2: 123-138.

Van Klaveren, Alberto. Continuidad y cambio en la política exterior chilena. En Di Tella, Torcuato. Argentina y Chile ¿Desarrollos paralelos? Buenos Aires: Nuevo Hacer-Isen, 1997.

- Inserción Internacional de Chile. En TOLOZA, Cristián y LAHERA, E. Chile en los noventa. Santiago: Presidencia de la República, Dirección de Estudios, 1998.

Waissbluth, Mario. La Reforma del Estado en Chile 1990-2005: Diagnóstico y Propuestas de Futuro, 2006. En [http://www.mariowaissbluth.com].

WiLHELmY, Manfred. Hacia un análisis de la política exterior chilena contemporánea. Estudios Internacionales, 1979, vol. 48, octubre-diciembre.

ZURBRIGGEN, Cristina. El institucionalismo centrado en los actores: una perspectiva analítica en el estudio de las políticas públicas. Revista de Ciencia Política, 2006, vol. 26: 67-83. 